\title{
Editorials
}

\section{Point-of-care testing for respiratory infections during and after COVID-19}

\section{INTRODUCTION}

The public's attitude to testing is likely to change in response to SARS-CoV-2 testing. We expect it will not be long before we are asked why tests are not offered for other respiratory infections. Prior to COVID-19, the initial management of most respiratory tract infections (RTIs) was conducted without microbiological testing, with many suggesting the consequent diagnostic uncertainty ${ }^{1}$ to be a leading cause of antibiotic overprescribing ${ }^{2}$ and resistance. ${ }^{3}$ Standard laboratory methods are too slow for initial decision making necessitating the use of rapid point-of-care testing. This technology, advocated as key to future antimicrobial stewardship, ${ }^{4}$ is now available and able to provide comprehensive respiratory virus panel results, including SARS-CoV-2, in 45 minutes. ${ }^{5-7}$

\section{POINT-OF-CARE TESTING}

Last winter, our team led the first exploratory investigation of the use of a multiviral point-of-care test using upper respiratory tract swabs in UK primary care. We found testing was acceptable to patients and improved clinician diagnostic certainty. ${ }^{8}$ However, clinicians were concerned about the absence of randomised trial evidence of effectiveness. ${ }^{8}$

While the upper respiratory tract is the only universally accessible location for sampling, swabbing is an inexact science. Even swabs taken by trained clinicians result in zero pathogen detection in up to $28 \%$ of symptomatic people. ${ }^{9-11}$ This likely represents suboptimal sampling, perhaps from an uncolonised region, rather than absence of pathogens in the respiratory tract. Conversely, in a small study published in 2017, we detected potentially pathogenic respiratory viruses in the upper respiratory tracts of $26 \%$ of asymptomatic children. ${ }^{9}$

Nonetheless, interest in the role of pointof-care testing for antimicrobial stewardship is growing. The 2014 National Institute
"Standard laboratory methods are too slow for initial decision making necessitating the use of rapid point- of-care testing. This technology ... is now available and able to provide comprehensive respiratory virus panel results, including SARS-COV-2, in 45 minutes.

for Health and Care Excellence adult pneumonia guidelines recommend the use of $\mathrm{C}$-reactive protein (CRP) testing in patients presenting to primary care with suspected community-acquired pneumonia. ${ }^{12}$ The recommendation is based on randomised controlled trial evidence demonstrating the effectiveness of CRP testing in reducing antibiotic prescribing. ${ }^{13-15}$ Yet 6 years later, the primary care uptake of CRP testing is remarkably low. Why?

We hypothesise that, in addition to unresolved discussions regarding who should pay for the test, clinicians may be uncertain as to how the test works. After all, an elevated CRP only indicates host immune activity, not that the infection is bacterial, nor that the infection has a poor prognosis. The mechanism by which CRP testing works could be simply that the low prevalence of elevated CRP in primary care, an element not always reported in the trials, ${ }^{13,14}$ more often than not favours a 'no antibiotic prescribing decision'. And test results are often regarded as 'objective' and 'true'; we rarely consider the impact of false positives and false negatives in day-to-day practice.

So, what is the prevalence of elevated CRP in primary care patients with acute lower RTI? In one study, of adults with acute cough, ${ }^{13}$ CRP was $\leq 20 \mathrm{mg} / \mathrm{L}$ in $69 \%$ of participants; 20 to $99 \mathrm{mg} / \mathrm{L}$ in $24 \%$; and $\geq 100 \mathrm{mg} / \mathrm{L}$ in $7 \%$. In another study, also of adults with acute cough, ${ }^{14}$ CRP was $\leq 20 \mathrm{mg} / \mathrm{L}$ in $70 \%$ of participants;
21 to $50 \mathrm{mg} / \mathrm{L}$ in $16 \%$; 51 to $99 \mathrm{mg} / \mathrm{L}$ in $9 \%$; and $\geq 100$ in $5 \%$ (B Stuart, personal communication, 2020). Finally, even in a trial of patients with acute exacerbation of COPD in whom CRP might be expected to be higher, ${ }^{15} \mathrm{CRP}$ was $<20 \mathrm{mg} / \mathrm{L}$ in $76 \%$; 20 to $40 \mathrm{mg} / \mathrm{L}$ in $12 \%$; and $>40 \mathrm{mg} / \mathrm{L}$ in $12 \%$. Thus, the effectiveness of CRP could be mediated through behaviour change in response primarily to the CRP result favouring a 'no-prescribing' decision eight to nine times out of 10 . It is therefore more important than ever to understand how CRP, and other point-of-care tests, work particularly in low disease prevalence settings like primary care.

\section{CONCLUSION}

In an emerging landscape where billions of dollars are being invested to develop test technology, ${ }^{16}$ and both patients and clinicians now consider results of upper respiratory tract swabbing to be an accurate reflection of their COVID-19 status, key research questions remain unanswered. What is the diagnostic and prognostic significance of the detection of bacteria and viruses from the upper respiratory tract? Do these tests provide diagnostic/prognostic value over and above symptoms and signs? How do they work to improve antibiotic prescribing, antibiotic consumption, and patient outcomes? And if they do work, are they clinically and cost-effective, and safe?

These questions are familiar to clinicians and medical scientists; they reflect the phase I to IV evidence base required before new medicines can be prescribed. Respiratory tract testing has now become mainstream and the widespread use of pointof-care microbial RTI tests is on the horizon. We believe these should be investigated in the same way as new medicines, ensuring appropriate use of public funds and enabling patients and clinicians to understand if the tests are useful tools, or costly distractions. 


\section{"We believe these [point-of-care tests] should be investigated in the same way as new medicines, ensuring appropriate use of public funds and enabling patients and clinicians to understand if the tests are useful tools, or costly distractions.}

\section{ADDRESS FOR CORRESPONDENCE}

\section{Alastair D Hay}

Centre of Academic Primary Care, NIHR School for Primary Care Research, Bristol Medical School: Population Health Sciences, Canynge Hall, 39 Whatley Road, Bristol BS8 2PS, UK

\section{Email: alastair.hayabristol.ac.uk}

\section{Hannah V Thornton}

Centre for Academic Primary Care, National Institute for Health Research (NIHR) School for Primary Care Research, Bristol Medical School, University of Bristol, Bristol.

\section{Tanzeela Khalid,}

Centre for Academic Primary Care, NIHR School for Primary Care Research, Bristol Medical School, University of Bristol, Bristol.

\section{Alastair D Hay,}

Centre for Academic Primary Care, NIHR School for Primary Care Research, Bristol Medical School, University of Bristol, Bristol.

\section{Provenance}

Freely submitted; externally peer reviewed.

\section{Competing interests}

BioMérieux provided point-of-care test machines for a recent study. ${ }^{8}$ The study purchased the testing kits and returned the machines to BioMérieux at the end of the study.

DOI: https://doi.org/10.3399/bjgp20X713561

\section{REFERENCES}

1. Horwood J, Cabral C, Hay AD, Ingram J. Primary care clinician antibiotic prescribing decisions in consultations for children with RTIs: a qualitative interview study. $\mathrm{Br} J \mathrm{Gen}$ Pract 2016; DOI: https://doi.org/10.3399/ bjgp16X683821.

2. Smieszek T, Pouwels KB, Dolk FCK, et al. Potential for reducing inappropriate antibiotic prescribing in English primary care. $J$ Antimicrob Chemother 2018; 73(suppl_2): ii36-ii43.

3. Costelloe C, Metcalfe C, Lovering A, et al. Effect of antibiotic prescribing in primary care on antimicrobial resistance in individual patients: systematic review and metaanalysis. BMJ 2010; 340: c2096.

4. O'Neill J. Tackling drug-resistant infections globally: final report and recommendations. 2016. https://amr-review.org/sites/default/ files/160518_Final\%20paper_with\%20cover. pdf laccessed 30 Oct 2020).

5. Biomérieux. BIOFIRE ${ }^{\circledR}$ respiratory 2.1 plus panel. 2020. https://www.biomerieuxdiagnostics.com/filmarrayr-respiratory-panel (accessed 30 Oct 2020)

6. GenMark Dx. Respiratory pathogen panels. 2020. https://www.genmarkdx.com/int/ solutions/panels/eplex-panels/respiratorypathogen-panel laccessed 30 Oct 2020).

7. QIAGEN. QIAstat-Dx respiratory SARS-CoV-2 panel: the next generation of syndromic insights. 2020. https://qiastat-dx.com/row/ wp-content/uploads/sites/3/2020/03/PROM15948-001_1121481_FLY_QIAstat-Dx-SARSCoV-2-CE-IVD_0320_ROW.pdf laccessed 30 Oct 2020)

8. Khalid T, Duncan L, Thornton HV, et al. Rapid respiratory microbiological point-of-care testing in primary care: mixed methods evaluation. Fam Pract 2020; in press.

9. Thornton HV, Hay AD, Redmond NM, et al. Throat swabs in children with respiratory tract infection: associations with clinical presentation and potential targets for pointof-care testing. Fam Pract 2017; 34(4) 407-415.

10. Regamey N, Kaiser L, Roiha HL, et al. Vira etiology of acute respiratory infections with cough in infancy: a community-based birth cohort study. Pediatr Infect Dis J 2008; 27(2): 100-105.

11. Rhedin S, Lindstrand A, Rotzén-Östlund M, et al. Clinical utility of PCR for common viruses in acute respiratory illness. Pediatrics 2014; 133(3): e538-545.

12. National Institute for Health and Care Excellence (NICE). Pneumonia: diagnosis and management of community- and hospitalacquired pneumonia in adults. London: NICE 2014

13. Cals JWL, Butler CC, Hopstaken RM, et al. Effect of point of care testing for $C$ reactive protein and training in communication skills on antibiotic use in lower respiratory tract infections: cluster randomised trial. $B M J$ 2009; 338: b1374

14. Little P, Stuart B, Francis N, et al. Effects of internet-based training on antibiotic prescribing rates for acute respiratorytract infections: a multinational, cluster, randomised, factorial, controlled trial. Lancet 2013; 382(9899): 1175-1182.

15. Butler CC, Gillespie D, White P, et al $C$-reactive protein testing to guide antibiotic prescribing for COPD exacerbations. $N$ Engl $J$ Med 2019; 381(2): 111-120.

16. Abbasi K. Covid-19: shooting for the moon. BMJ 2020; 370: m3509. 